\title{
Use of an incubator in a group general practice
}

\author{
DONALD W GAU, GILLIAN S GAU
}

British Medical fournal, 1979, 2, 1481-1482

Although in Britain hospital laboratory facilities are freely available to most general practitioners, some group practices have chosen to perform their own basic laboratory investigations. ${ }^{1-t}$ Such laboratory procedures, however, remain limited to only a few practices-probably for two main reasons: firstly, microbiologists' anxiety about the maintenance of quality control, and, secondly, general practitioners' disinterest.

The chance acquisition of a redundant incubator from the local district hospital combined with the co-operation of the local microbiological department allowed us to study how these problems could be overcome in a group general practice.

\section{The practice}

The practice consists of six partners who have been principals between four and 35 years. They practise from two converted houses ${ }^{5}$ and look after 13000 patients in semi-rural surroundings. During the year of the study there were also two trainees in the practice.

\section{Materials}

A small room in the main centre was adapted to hold the incubator (Charles Hearson and Co Ltd), a domestic refrigerator, and a table. $A$ hand basin was installed and a pathological day book started. The local microbiological laboratory supplied $5 \mathrm{~cm}$ sterilin dishes with

Middlesex Hospital, London W1, and Penn, Bucks DONALD W GAU, MRCP, MRCGP, senior lecturer in general practice and
general practitioner

Queen Charlotte's Hospital, London W6 0XG

GILLIAN S GAU, MD, senior registrar in morbid anatomy

commercial blood agar and MacConkey's (CM 7B Oxoid) and Sabouraud's agar, which were stored in the refrigerator. Penicillin discs were used when necessary. All swabs were taken with serumcoated Exogen swabs. The incubator in the main centre and a Ceduran dipslide incubator in the branch surgery were adjusted to $37^{\circ} \mathrm{C}$. The local microbiologist advised on safety, and his department disposed of used swabs and plates, which were sent to the hospital in sealed plastic bags.

\section{Method}

Patients who presented with relevant symptoms were selected according to the interest of the doctor. At first interview patients were given a prescription for an appropriate antibiotic, which they were to obtain should the swab be positive next day. Patients were asked to telephone for the results.

Sore throats-Throat swabs were plated on to blood agar at the end of surgery and after morning or afternoon visits. The plates were read between 17 and 22 hours after plating out.

Urinary tract symptoms-Midstream specimens of urine were plated out within two hours of voiding, using the blotting-paper method, as described. 6 The start of treatment depended on the severity of symptoms. Positive plates were sent to the local hospital for sensitivity testing.

Vaginal discharge-High vaginal swabs were plated on to Sabouraud's medium and read at 24 and 48 hours.

Skin lesions-Direct swabs from the skin lesions were plated on to either blood agar incorporated with penicillin discs or Sabouraud's medium.

\section{QUALITY CONTROL}

At first each partner spent one week reporting plates. Eventually most plates were reported by only one of the partners. Quality control was instituted by the chief microbiological technician from the local hospital, who came daily for the first six weeks and checked the plates with each practitioner. For the rest of the year positive midstream urine results were forwarded to the laboratory at the discretion of the patient's own doctor. Random throat and vaginal swabs were also sent for checking. 


\section{Results}

During the year 1110 swabs were taken, of which 384 (35\%) were positive (table).

Number of swabs taken over one year with the absolute number and percentagepositive results in each group

\begin{tabular}{|c|c|c|c|c|}
\hline \multicolumn{3}{|c|}{ Area swabbed } & \multirow{2}{*}{$\begin{array}{c}\text { No taken } \\
809 \\
121 \\
144 \\
36\end{array}$} & \multirow{2}{*}{$\begin{array}{c}\text { No positive } \\
275(34 \%) \\
28(23 \%) \\
45(31 \%) \\
20(55 \%)\end{array}$} \\
\hline $\begin{array}{l}\text { Throat } \quad . \\
\text { Vagina } \quad . \\
\text { Urine } \\
\text { Miscellaneous }\end{array}$ & $\begin{array}{l}\cdots \\
\therefore \\
\cdots\end{array}$ & $\begin{array}{l}\ldots \\
\therefore \\
\therefore\end{array}$ & & \\
\hline
\end{tabular}

Throat swabs-Of the 809 throat swabs taken, $275(34 \%)$ showed more than two colonies with beta-haemolysis and were therefore deemed positive. The percentage of positive throat swabs remained constant throughout the year, with the absolute number of swabs taken monthly falling only between August and November.

High vaginal swabs-One hundred and twenty-one high vaginal swabs were taken. Any matt colonies were considered monilial and reported as positive. Twenty-eight $(23 \%)$ were positive.

Midstream urine test-Forty-five $(31 \%)$ of 144 specimens were positive. Any strip with a pure growth of a lactose-fermenting organism was considered positive. Mixed growths were repeated.

\section{Discussion}

The problem of quality control appears to have been largely overcome thanks to a sympathetic and helpful local microbiological department. Initial training of doctors and spot checks at the laboratory have maintained a high level of diagnostic accuracy. The fact that the percentage of positive beta-haemolytic streptococcal (BHS) throat swabs is similar to that found in a previous study in this practice," where the swabs were sent to the local hospital, further supports this claim. This incidence also agrees with that found in other studies. ${ }^{2}$ Interestingly, these results have been achieved without using subculture or $\mathrm{CO}_{2}$-enriched atmosphere. The fixed ratio of BHS may have been influenced by the absence of an epidemic during the year, but the quarterly incidence of throat swabs in this study parallels the incidence of sore throats and tonsillitis reported by the Office of Population Censuses and Surveys for $1978 .^{8}$

The acquisition by the practitioners of the skill of identifying organisms means that bacteriological reports from the hospital are now read with more scepticism and perhaps more realism than before. The awareness that not all dysuria or sore throats need antibiotics has been emphasised. After initial resistance patients have come to expect and even ask for a swab to be taken rather than for a prescription for penicillin.

Clearly the telephone has played an essential part in this study, which may limit this type of practice to those areas where patients are used to telephones. With suitable interest, however, this could be overcome in areas where the centre is within easy reach of most patients.

The effect on the hospital laboratory is difficult to gauge. Clearly the practice would not normally take over 800 throat swabs annually if they were to be sent to the hospital. Because of this we cannot claim to have reduced its work load by this figure-in fact, the laboratory has had to make 800 blood agar plates not normally required. The NHS has benefited financially in that 500 fewer penicillin prescriptions have been presented. As at least one or two patients are likely to have had adverse side effects they too must also have benefited.

There were fewer urine specimens but the financial benefit could still be appreciable as general practitioners tend to use expensive antibiotics for symptoms of dysuria. This would mean that even a moderate decrease in the number of unnecessary prescriptions would be worth while.

As a high vaginal swab negative for monilia must automatically be investigated for trichomonas the saving in time and money is negligible. We are concerned that Neisseria gonorrhoeae is not being looked for and are at present exploring how we could include it.

That general practitioners have no interest in using an incubator has clearly been disproved. In this practice six doctors who had acquired one by chance used it over 1000 times in one year. The only motive at first was to justify the incubator "because it was there" and not an overriding interest in altering prescribing habits or extending their knowledge of the microbiological flora of the practice. Encouragingly, the two trainees introduced the use of incubators to the practices in which they finally settled as they found it an essential part of their day-to-day work. With this enthusiasm the use of the incubator could be greatly increased, with consequent saving in the hospital laboratory and in the community. But perhaps the main benefit is the education of both doctor and patient into a clearer understanding of pathological processes.

We thank Dr Donald Leigh and Mr Roy Barrow, of the department of microbiology, Wycombe General Hospital, for their invaluable support and assistance.

This work was supported by a grant from Oxford Regional Board.

\section{References}

1 Grob, P R, Proceedings of the Royal Society of Medicine, 1977, 70, 715.

${ }^{2}$ Manners, B T M, Proceedings of the Royal Society of Medicine, 1977, $70,721$.

${ }^{3}$ Suffield, W E, Calvert, J W, and Suffield, S B, fournal of the Royal College of General Practitioners, 1973, 23, 344.

4 MacNaughtan, G, Current Medical Abstracts for Practitioners, 1965, 5, 45.

5 Gau, D W, and Solomon, R M, Fournal of the Royal College of General Practitioners, 1977, 27, 735.

- Leigh, D A, and Williams, J D, fournal of Clinical Pathology, 1964, 17, 498.

${ }^{7}$ Gau, D W, et al, The Practitioner, 1972, 208, 276.

8 Office of Population Censuses and Surveys, Monitor, 1978.

(Accepted 24 September 1979)

During a year working in Scotland I treated many alcoholics and yet saw only one case of alcoholic cardiomyopathy. I then spent a year in New Zealand where I treated a roughly similar number of alcoholics and saw at least a dozen cases of alcoholic cardiomyopathy. Was this impression of a far greater prevalence of alcoholic cardiomyopathy in New Zealand correct, and if so why should it be?

Heart failure occurring in chronic alcoholics should be described as "alcoholic heart muscle disease" rather than "cardiomyopathy," a label which should be reserved for those entities where the cause or causes of heart muscle disease are unknown. ${ }^{1}$ Though alcohol has a deleterious effect on the myocardium, ${ }^{2}$ congestive heart failure due to alcohol is relatively rare-1-2\% of chronic alcoholics. ${ }^{3}$ One obvious explanation could be that the frequent encounter of such patients in New Zealand was in centres specialising in that type of heart disease. A second explanation could be that the type of alcoholic beverage consumed differed in the two countries, being, presumably, whisky in Scotland and beer in New Zealand. "Beer drinker's heart" has occurred in Munich and "beer-drinker's cardiomyopathy" in Canada and Belgium. The cause was finally traced back to high amounts of cobalt in beer, an unlikely possibility to-day. If the above suggestions can be eliminated with certainty further investigative work should be undertaken to resolve the striking discrepancy of incidence of heart failure due to alcohol in Scotland and New Zealand.

'Olsen, E G J, British Medicine, 1978, 7 June, 53.

2 . 2 Klein, H, and Harmjanz, D, Postgraduate Medical fournal, 1975, 51, 325.
Fink, R, Marjot, D H, and Rosalki, S B, Annals of Clinical Biochemistry, 1979,

Is there any evidence that the children of toxaemic pregnancies suffer more "cot deaths"?

There is no known association between pregnancy toxaemia and sudden unexplained deaths (cot deaths). 